\title{
STRATEGI PERUSAHAAN DALAM MEMINIMALISIR TERJADINYA SELISIH BARANG ANTARA STOCK ON HAND DENGAN STOCK ACTUAL
}

\author{
Somadi $^{1}$, Nabillah Jullanaar Karwan ${ }^{2}$ \\ D4 Logistik Bisnis, Politeknik Pos Indonesia ${ }^{1}$ \\ email: somadi@poltekpos.ac.id ${ }^{1}$ \\ D4 Logistik Bisnis, Politeknik Pos Indonesia ${ }^{2}$ \\ email: nabiil.jullanaar@gmail.com²
}

\begin{abstract}
Abstrak
PLB Batujajar merupakan pusat logistik berikat yang dimiliki oleh PT Agility International. Namun dalam aktivitas proses inbound di PLB Batujajar terjadinya selisih barang antara stock on hand dengan stock actual sehingga membuat perusahaan harus memberikan ganti rugi dan menerima komplain dari customer. Tujuan penelitian ini untuk mengetahui faktor penyebab terjadinya selisih barang, dan langkah-langkah yang harus dilakukan untuk meminimalisir terjadinya selisih barang stock on hand dengan stock actual. Metode penelitian menggunakan pendekatan kualitatif dengan teknik analisis fishbone diagram dan analisis $5 \mathrm{~W}+1 \mathrm{H}$. Berdasarkan hasil penelitian, bahwa faktor penyebab terjadinya selisih barang karena karyawan tidak teliti saat bekerja, barang sulit dihitung karena ukuran barang berbeda-beda, dan sistem perhitungan yang masih manual. Langkah-langkah yang harus dilakukan untuk meminimalisir terjadinya selisih barang yakni memberikan pelatihan tentang penerimaan barang di gudang, sosialisasi SOP inbound barang secara berkala, pengelompokan barang untuk penyimpanan barang di pallet berdasarkan kesamaan ukuran barang, dan melakukan pembaharuan teknologi agar perhitungan menjadi terkomputerisasi.
\end{abstract}

Kata Kunci: strategi perusahaan, stock on hand, stock actual, fishbone diagram, analisis $5 \mathrm{~W}+1 \mathrm{H}$

\begin{abstract}
PLB Batujajar is a bonded logistics center owned by PT Agility International. However, in the inbound process activities at PLB Batujajar there is a difference in goods between the stock on hand and the actual stock so that the company has to provide compensation and receive complaints from customers. The purpose of this study is to determine the factors causing the difference in goods, and steps that must be taken to minimize the difference between stock on hand and actual stock. The research method used a qualitative approach with fishbone diagram analysis techniques and $5 \mathrm{~W}+1 \mathrm{H}$ analysis. Based on the results of the study, that the factors causing the difference in goods are because employees are not careful when working, goods are difficult to count because the sizes of goods are different, and the calculation system is still manual. Steps that must be taken to minimize the occurrence of differences in goods, namely providing training on receiving goods in warehouses, socializing periodic inbound goods SOPs, grouping goods for storage of goods on pallets based on the same size of goods, and carrying out technological updates so that calculations become computerized.
\end{abstract}

Keywords: corporate strategy, stock on hand, actual stock, fishbone diagram, $5 W+1$ H analysis

\section{PENDAHULUAN}

Pusat Logistik Berikat (PLB) merupakan tempat penimbunan barang yang berasal luar daerah Pabean atau tempat lain dalam daerah Pabean dalam jangka waktu tertentu, yang dapat disertai 1 (satu) atau lebih kegiatan sederhana. Hal ini sesuai dengan definisi PLB berdasarkan Peraturan Pemerintah Republik Indonesia Nomor 85 Tahun 2015 bahwa PLB adalah tempat penimbunan berikat untuk menimbun barang asal luar daerah Pabean dan/atau barang yang berasal dari tempat lain dalam daerah Pabean, dapat disertai satu atau lebih kegiatan sederhana dalam jangka waktu tertentu untuk dikeluarkan 
kembali (Widodo, 2015). PLB memiliki keunggulan yakni adanya penangguhan bea masuk, tidak adanya pemungutan pajak dalam rangka impor (PDRI), pembebasan cukai ketika barang masuk ke PLB, tidak adanya pemungutan PPN dan pajak penjualan atas barang mewah, adanya fleksibilitas terkait dengan masa timbun barang yang mencapai 3 tahun, adanya fleksibilitas terhadap kepemilikan barang, adanya kecepatan layanan karena PLB telah menggunakan Warehouse Management System (WMS), dan terakhir bahwa nilai Pabean digunakan saat barang dikeluarkan dari PLB.

Kebijakan insentif yang diberikan kepada perusahaan yang bergerak pada bidang PLB memberikan dampak positif berupa penurunan dwelling time di Pelabuhan. Hal ini disebabkan karena adanya pemindahan beberapa kegiatan yakni pre-clearance dan custom clearance dari pelabuhan menuju PLB. Selain itu juga, kebijakan tersebut memberikan kemudahan dan efisiensi produksi pada industri nasional.

Saat ini perkembangan PLB di Indonesia semakin banyak. Dengan semakin banyaknya jumlah PLB tersebut diharapkan adanya penuruna biaya logistik nasional sehingga membuat daya saing industri nasional akan semakin baik (Haryana, 2016). PT. Agility International merupakan salah satu perusahaan yang bergerak pada bidang PLB. Lokasi PLB PT Agility International terdapat di berbagai daerah, salah satunya berada di PLB Batujajar. Adapun aktivitas yang ada di PLB Batujajar yakni salah satunya proses handling barang.

Dalam proses handling barang di PLB Batujajar PT. Agility International terdapat permasalahan yakni terjadinya selisih barang stock on hand dengan stock actual. Selisih barang yang terjadi adalah ketidaksesuaian stock on hand dalam sistem dengan stock actual (fisik) setelah dilakukannya proses pembongkaran barang dari container. Selama bulan September 2019 sampai dengan bulan Desember 2019 terdapat selisih barang sebanyak 66 kali. Berikut data banyaknya selisih yang terjadi selama bulan September 2019 sampai dengan Desember 2019

Tabel 1. Data Selisih Barang (Satuan Unit Container) Bulan September 2019 s/d Desember 2019

\begin{tabular}{|c|c|c|c|c|}
\hline Bulan & $\begin{array}{c}\text { Jumlah } \\
\text { Bongkar }\end{array}$ & $\begin{array}{c}\text { Data yang sesuai antara } \\
\text { sistem dengan aktual }\end{array}$ & $\begin{array}{c}\text { Data yang tidak sesuai } \\
\text { antara sistem dengan aktual }\end{array}$ & Persentase \\
\hline September & 117 & 84 & 33 & 28 \\
\hline Oktober & 83 & 68 & 15 & 18 \\
\hline November & 125 & 109 & 16 & 13 \\
\hline Desember & 92 & 90 & 2 & 2 \\
\hline & 417 & 351 & 66 & \\
\hline
\end{tabular}

Sumber: Hasil Pengolahan Data, 2020

Berdasarkan tabel di atas bahwa bulan Agustus terdapat jumlah bongkar sebanyak 117 container, namun container yang sesuai hanya 84 container sehingga ada selisih sebanyak 33 container (28\%), sedangkan pada bulan September terdapat jumlah bongkar sebanyak 83 container dengan jumlah container yang sesuai sebanyak 68 container sehingga ada selisih sebanyak 15 container (18\%). Sementara itu, pada bulan Oktober terdapat jumlah bongkar sebanyak 125 container dengan container yang sesuai sebanyak 109 container sehingga ada selisih sebanyak 16 container (13\%), dan pada bulan November terdapat jumlah bongkar sebanyak 92 container, dengan container yang sesuai sebanyak 90 container sehingga ada selisih sebanyak 2 container ( $2 \%)$.

Meskipun mengalami penurunan terkait dengan permasalahan selisih barang, namun hal ini tetap perlu dilakukan identifikasi penyebab terjadinya selisih barang dan mencari solusi untuk mengatasi permasalahan tersebut. Hal ini disebabkan karena apabila permasalahan selisih barang terus terjadi, maka akan berdampak terhadap kerugian perusahaan karena perusahaan harus memberikan ganti rugi dan membayarkan ganti rugi tersebut kepada customer. Selain itu juga perusahaan menerima banyak komplain dari para customer yang dapat berdampak pada penurunan citra perusahaan dan hilangnya customer perusahaan karena customer lebih memilih perusahaan lain yang memberikan pelayanan yang sesuai dengan kebutuhan dan keinginanya.

Customer yang melakukan komplain kepada perusahaan karena customer tidak merasa puas terhadap apa yang diterimanya, sehingga hal tersebut harus menjadi perhatian serius dari perusahaan agar permasalahan complain customer tidak terjadi lagi pada periode selanjutnya (Somadi \& Hidayat, 2019). Complain customer juga terjadi karena perusahaan dalam operasionalnya jarang melakukan penelitian ataupun penerapan strategi dalam memperbaiki kualitas pelayanannya, sehingga perlu dilakukan 
pengendalian kualitas pelayanan agar perusahaan dapat bersaing dalam bisnis, konsumen percaya kepada perusahaan, dan peningkatan nilai jual (Somadi, Priambodo, et al., 2020). Apabila nilai jual berkurang, maka diindikasikan akan menurunkan tingkat profit. Penurunan profit tersebut disebabkan karena terjadinya penurunan penggunaan produk perusahaan yang dilakukan oleh konsumen karena konsumen beralih untuk memilih produk yang ditawarkan oleh perusahaan lain (Somadi, 2020). Untuk itu, perusahaan harus tetap menjaga kualitas pelayanannya kepada konsumen agar konsumen merasa puas. Dengan tingginya tingkat kepuasan yang dirasakan oleh konsumen, maka konsumen kemungkinan besar akan loyal kepada produk perusahaan, karena apa yang diharapkannya dalam menggunakan produk perusahaan telah tercapai.

Dengan memperhatikan berbagai permasalahan yang ada dan dampak yang ditimbulkan dari permasalahan tersebut. Maka perlu dilakukan penelitian guna merancang strategi guna meminimalisir terjadinya selisih barang. Untuk itu, tujuan penelitian ini yakni untuk mengetahui faktor penyebab terjadinya selisih barang stock on hand dengan stock actual, serta langkah-langkah yang harus dilakukan untuk meminimalisir terjadinya selisih barang stock on hand dengan stock actual di PLB Batujajar PT Agility International.

\section{METODE PENELITIAN}

Metode penelitian menggunakan metode kualitatif dengan teknik analisis fishbone diagram dan analisis $5 \mathrm{~W}+1 \mathrm{H}$. Analisis fishbone diagram digunakan untuk mencari akar penyebab permasalahan terjadinya selisih barang, sedangkan analisis $5 \mathrm{~W}+1 \mathrm{H}$ bertujuan untuk merancang strategi perbaikan untuk mengatasi permasalahan terjadinya selisih barang di PLB Batujajar PT Agility International. Adapun langkah-langkah dalam menggunakan analisis fishbone diagram antara lain:

a. Pengumpulan data.

b. Menggambarkan bagan faktor penyebab;

c. Identifikasi akar masalah;

d. Rekomendasi dan implementasi (Hamidy, 2016).

Sementara itu, langkah-langkah dalam melakukan analisis $5 \mathrm{~W}+1 \mathrm{H}$ antara lain sebagai berikut:

a. What, bermakna apa yang menjadi permasalahan sehingga perlu dilakukan perbaikan?

b. Why, bermakna alasan mengapa perlu dilakukan perbaikan pada permasalahan tersebut?

c. Where, bermakna dimana lokasi yang akan dilakukan?

d. When, bermakna kapan kegiatan perbaikan akan dilakukan di perusahaan?

e. Who, bermakna siapa pihak yang akan bertanggungjawab terhadap aktivitas perbaikan yang akan dilakukan?

f. How, bermakna bagaimana strategi untuk mengatasi permasalahan yang akan dilakukan perbaikan? (Somadi \& Hidayat, 2019).

Jenis data yang digunakan dalam penelitian menggunakan data sekunder dan data primer. Data primer diperoleh dengan menggunakan teknik pengumpulan data yakni studi dokumentasi, sedangkan data primer diperoleh dengan menggunakan teknik pengumpulan data yakni observasi dan wawancara kepada pihak perusahaan. Adapun pihak perusahaan yang menjadi narasumber guna penggalian informasi yakni staf inbound, dan tenaga kerja bongkar muat (TKBM) dan manajer inbound. Adapun subjek dalam penelitian ini yakni Gudang PLB Batujajar PT. Agility International, sedangkan objek penelitian ini yakni selisih barang stock on hand dengan stock actual.

\section{HASIL DAN PEMBAHASAN}

Aktivitas proses handling di PLB Batujajar PT. Agility International memerlukan beberapa tahapan antara lain sebagai berikut:

1) Input

Alur kegiatan di PLB Batujajar PT. Agility International diawali dengan barang yang dikirimkan oleh shipper yang berasal dari luar negeri. Hal ini disebabkan karena PT Agility Internatioanl hanya menangani barang-barang impor. Adapun shipper yang mengirim barang tersebut merupakan perusahaan yang bergerak dalam bidang manufaktur. Perusahaan manufaktur tersebut mengirimkan barangnya sesuai dengan permintaan importir yang ada di Indonesia yang bekerja 
sama dengan PLB Batujajar PT. Agility International. Sehingga barang yang dikirimkan oleh shipper disimpan terlebih dahulu di PLB Batujajar PT. Agility International.

2) Process

Setelah container/truck yang membawa barang dari shipper tiba di warehouse, maka tahap selanjutnya dilakukan proses penanganan barang. Berikut adalah proses terhadap penanganan barang dari shipper yang dilakukan di PLB Batujajar PT. Agility International:

a. Receiving

Penerimaan barang (receiving) yang dilakukan oleh tim inbound harus memenuhi standard operational procedure (SOP) yang berlaku di perusahaan. Pertama, tim inbound akan melakukan proses pengecekan dokumen, dan apabila dokumen telah sesuai maka akan dilakukan proses pembongkaran barang. Kemudian tahap selanjutnya tim inbound akan melakukan pengecekan barang dengan Packing List. Setelah itu dilakukan pencatatan laporan penerimaan barang di form Inbound Tally Sheet. Form Inbound Tally Sheet tersebut merupakan laporan terhadap quantity dan deskripsi barang yang diterima oleh tim inbound.

b. Storage

Penyimpanan dilakukan setelah proses penerimaan barang yang dilakukan tim inbound selesai. Kemudian, tim inbound akan mencari lokasi kosong untuk penyimpanan barang tersebut. Setelah ditemukan lokasi kosong, maka barang disimpan di lokasi tersebut dan diberi label barang yang telah disiapkan.

c. Outgoing

Pada proses ini akan dilakukan pengecekan barang, dan biasanya terjadi kesalahan pada proses ini akibat dari ketidaktelitian checker dalam melakukan proses pengecekan barang di storage sebelum barang dimuat ke container/truck. Pada tahap ini diperlukan ketelitian checker dalam melakukan pengecekan dan perhitungan terhadap barang yang akan dikirim.

3) Output

Setelah proses outgoing selesai, maka barang yang akan dikirimkan akan dimuat ke container/truck untuk dikirimkan ke pihak customer/importir dan akan memproses segala dokumen yang dibutuhkan untuk pengiriman.

Berdasarkan hasil penelitian pada proses handling yang ada di PLB Batujajar PT Agility International terdapat beberapa faktor penyebab terjadinya selisih barang. Berikut ini adalah hasil analisis penyebab terjadinya selisih barang dengan menggunakan fishbone diagram.

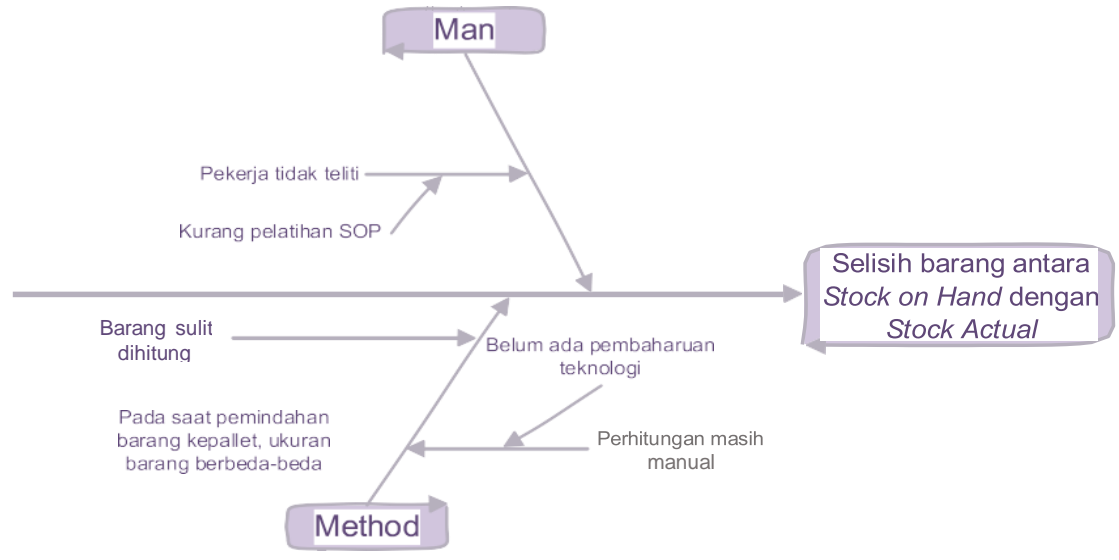

Gambar 1. Fishbone Diagram Selisih Barang antara Stock On Hand dengan Stock Actual Sumber: Hasil Pengolahan Data, 2020

Gambar diatas menjelaskan beberapa faktor yang menyebabkan terjadiya selisih barang antara stock on hand dengan stock actual di PLB Batujajar PT. Agility International. Permasalahan selisih barang antara stock on hand dengan stock actual disebabkan oleh dua faktor utama yaitu faktor man dan 
methode. Permasalahan man karena pekerja tidak teliti dalam melakukan pekerjaannya yakni kesalahan dalam perhitungan barang. Ketidaktelitian yang dilakukan para pekerja karena para pekerja kurang mendapatkan sosialisasi tentang SOP inbound barang, padahal SOP inbound barang sudah ada di perusahaan. Sementara itu untuk faktor method disebabkan karena pada saat proses perhitungan, sistem yang digunakan masih manual karena saat ini belum adanya pembaharuan teknologi untuk perhitungan barang di perusahaan. Kemudian penyebab kedua pada faktor method karena barang sulit dihitung saat proses perhitungan barang karena ukuran barang berbeda-beda. Kesalahan ini terjadi ketika proses pemindahan barang ke pallet.

Berdasarkan penelitian dari Syahruddin, bahwa faktor penyebab terjadinya selisih jumlah stok suku cadang yang terdata dengan yang tersedia di gudang karena barang pindah ke gudang baru, pengeluaran tanpa FPB (form pengeluaran barang), salah pemotongan, dan dilakukan peng-adjust-an (Syahruddin, 2016). Hasil penelitian ini juga senada yang dilakukan oleh Syam, bahwa penyebab kesalahan dalam proses picking dan shipping warehouse management karena human error yang disebabkan karena faktor situasional dan individual (Syam, 2015).

Dengan demikian untuk mengatasi permasalahan selisih barang antara stock on hand dengan stock actual, maka diperlukan rancangan strategi perbaikan. Untuk membuat rancangan perbaikan menggunakan analisis $5 \mathrm{~W}+1 \mathrm{H}$. Berikut adalah analisis $5 \mathrm{~W}+1 \mathrm{H}$ untuk proses perbaikan guna meminimalisir permasalahan selisih barang yang terjadi di PLB Batujajar PT Agility International.

Tabel 2. Analisis $5 \mathrm{~W}+1 \mathrm{H}$

\begin{tabular}{|c|c|c|c|c|c|c|c|c|}
\hline No & Faktor & $\begin{array}{l}\text { Penyebab } \\
\text { Utama }\end{array}$ & What & Why & When & Where & Who & How \\
\hline 1 & Man & $\begin{array}{l}\text { Kurang } \\
\text { sosialisasi } \\
\text { tentang SOP } \\
\text { inbound } \\
\text { barang }\end{array}$ & $\begin{array}{l}\text { Karyawan } \\
\text { tidak teliti } \\
\text { saat bekerja }\end{array}$ & $\begin{array}{l}\text { Agar } \\
\text { karyawan } \\
\text { dapat bekerja } \\
\text { dengan teliti } \\
\text { sehingga } \\
\text { adanya } \\
\text { peningkatan } \\
\text { dalam standar } \\
\text { kerja } \\
\text { karyawan }\end{array}$ & $\begin{array}{l}\text { Setiap } \\
3 \\
\text { bulan } \\
\text { sekali }\end{array}$ & Gudang & $\begin{array}{l}\text { Tim } \\
\text { Inbound }\end{array}$ & $\begin{array}{l}\text { Memberikan } \\
\text { pelatihan tentang } \\
\text { penerimaan } \\
\text { barang di gudang } \\
\text { dan sosialisasi } \\
\text { mengenai SOP } \\
\text { inbound barang } \\
\text { secara berkala }\end{array}$ \\
\hline 2 & Method & $\begin{array}{l}\text { Ukuran } \\
\text { barang yang } \\
\text { berbeda-beda } \\
\text { saat proses } \\
\text { pemindahan } \\
\text { barang ke } \\
\text { pallet }\end{array}$ & $\begin{array}{l}\text { Barang } \\
\text { yang sulit } \\
\text { dihitung } \\
\text { saat proses } \\
\text { bongkar } \\
\text { barang }\end{array}$ & $\begin{array}{l}\text { Agar } \\
\text { memudahkan } \\
\text { karyawan saat } \\
\text { proses } \\
\text { perhitungan } \\
\text { barang }\end{array}$ & $\begin{array}{l}\text { Setiap } \\
\text { hari }\end{array}$ & Gudang & $\begin{array}{l}\text { Tim } \\
\text { Inbound }\end{array}$ & $\begin{array}{l}\text { Melakukan } \\
\text { pengelompokan } \\
\text { barang untuk } \\
\text { penyimpanan } \\
\text { barang di pallet } \\
\text { berdasarkan } \\
\text { kesamaan ukuran } \\
\text { barang yang ada }\end{array}$ \\
\hline & & $\begin{array}{l}\text { Belum } \\
\text { adanya } \\
\text { pembaharuan } \\
\text { teknologi }\end{array}$ & $\begin{array}{l}\text { Sistem } \\
\text { perhitungan } \\
\text { yang masih } \\
\text { manual }\end{array}$ & $\begin{array}{l}\text { Agar } \\
\text { memudahkan } \\
\text { saat proses } \\
\text { perhitungan } \\
\text { barang dan } \\
\text { meminimalisir } \\
\text { terjadinya } \\
\text { kesalahan } \\
\text { dalam proses } \\
\text { perhitungan } \\
\text { barang }\end{array}$ & $\begin{array}{l}\text { Setiap } \\
\text { hari }\end{array}$ & Gudang & $\begin{array}{l}\text { Tim } \\
\text { Inbound }\end{array}$ & $\begin{array}{l}\text { Melakukan } \\
\text { pembaharuan } \\
\text { teknologi agar } \\
\text { perhitungan } \\
\text { menjadi } \\
\text { terkomputerisasi }\end{array}$ \\
\hline
\end{tabular}

Sumber: Hasil Pengolahan Data, 2020

Dengan demikian, berdasarkan hasil analisis yang telah dilakukan yakni telah diketahuinya faktor penyebab terjadinya selisih barang stock on hand dengan stock actual, maka perusahaan diharapkan segera melaksakana berbagai strategi untuk mengatasi permasalahan tersebut. Hal tersebut bertujuan agar tingkat kepuasan konsumen tetap terjaga. Untuk itu perusahaan segera melakukan perbaikan 
kualitas pelayanan yang diberikan kepada pelanggannya agar terciptanya kepuasan pelanggan. Hal tersebut tentunya akan berdampak positif bagi peningkatan citra perusahaan dan keuntungan yang diraih oleh konsumen maupun perusahaan. Apabila kualitas pelayanan yang diberikan oleh perusahan kurang baik dan tidak segera dilakukan perbaikan, maka akan berdampak sebaliknya yaitu konsumen akan menjadi tidak puas, dan konsumen akan meninggalkan perusahaan (Somadi, Pasaribu, et al., 2020).

\section{KESIMPULAN DAN SARAN}

Berdasarkan hasil analisis yang telah dilakukan, maka dapat disimpulkan bahwa faktor penyebab terjadinya selisih barang stock on hand dengan stock actual karena karyawan tidak teliti saat bekerja karena kurangnya sosialisasi tentang SOP inbound barang, barang yang sulit dihitung saat proses bongkar barang karena ukuran barang yang berbeda-beda saat proses pemindahan barang ke pallet, dan sistem perhitungan yang masih manual karena belum adanya pembaharuan teknologi. Adapun langkahlangkah yang harus dilakukan untuk meminimalisir terjadinya selisih barang stock on hand dengan stock actual di PLB Batujajar PT Agility International yakni memberikan pelatihan tentang penerimaan barang di gudang dan sosialisasi mengenai SOP inbound barang secara berkala, melakukan pengelompokan barang untuk penyimpanan barang di pallet berdasarkan kesamaan ukuran barang yang ada, dan melakukan pembaharuan teknologi agar perhitungan menjadi terkomputerisasi. Bagi penelitian selanjutnya, diharapkan dapat memetakan faktor penyebab yang memiliki pengaruh dominan dalam terjadinya selisih barang stock on hand dengan stock actual di actual di PLB Batujajar PT Agility International.

\section{REFERENSI}

Widodo, J. (2015). Peraturan Pemerintah Republik Indonesia Nomor 85 Tahun 2015 Tentang Perubahan Atas Peraturan Pemerintah Nomor 32 Tahun 2009 Tentang Tempat Penimbunan Berikat. In Menteri Hukum dan Hak Asasi Manusia Republik Indonesia (pp. 1-24). Menteri Hukum dan Hak Asasi Manusia Republik Indonesia.

Haryana, A. (2016). Peran Pusat Logistik Berikat (PLB) Dalam Menurunkan Dwelling Time di Pelabuhan Indonesia. Jurnal Cendekia Niaga, 1(1), 1-10.

Somadi, S., \& Hidayat, F. (2019). Rancangan Strategi Untuk Mengatasi Penolakan Truk Dan Kontainer Oleh Customer. Jurnal Logistik Bisnis, 9(2), 118-124. https://doi.org/10.46369/logistik.v9i02.574

Somadi, S., Priambodo, B. S., \& Okarini, P. R. (2020). Evaluasi Kerusakan Barang Dalam Proses Pengiriman Dengan Menggunakan Metode Seven Tools. Jurnal Intech Teknik Industri Universitas Serang Raya, 6(1), 1-11. https://doi.org/10.30656/intech.v6i1.2008

Somadi, S. (2020). Penilain Tingkat Kesehatan Keuangan PT Pos Indonesia (Persero) Periode 2016-2018. Bisma: Jurnal Bisnis Dan Manajemen, 14(1), 19-33. https://doi.org/10.1002/nme.607

Hamidy, F. (2016). Pendekatan Analisis Fishbone Untuk Mengukur Kinerja Proses Bisnis Informasi E-Koperasi. Jurnal Teknoinfo, 10(1), 1-3. https://doi.org/10.33365/jti.v10i1.12

Syahruddin, S. (2016). Analisis Faktor-Faktor Penyebab Terjadinya Selisih Jumlah Stok Suku Deskripsi Item Suku cadang Prosentase Item Suku cadang yang tidak bermasalah Item Suku cadang yang terjadi selisih Stok Jumlah Item suku cadang. Jurnal Teknologi Terpadu, 4(1), 42-47.

Syam, S. (2015). Human Error Dalam Proses Picking dan Shipping Warehouse Management di PT Cipta Krida Bahari Samarinda. 2(1), 1-16.

Somadi, S., Pasaribu, D. A., \& Khoiriyah, R. (2020). Evaluasi Pemilihan Penyedia Jasa Truk Angkutan Barang Menggunakan Metode Simple Additive Weighting. Jurnal Nusantara Aplikasi Manajemen Bisnis, 5(2), 91-112. https://doi.org/https://doi.org/10.29407/nusamba.v5i2.14508 